\title{
ANTI-CHOLOSETEROL ACTIVITIES OF WHITE (RAPHANUS RAPHANISTRUM) AND RED (RAPHANUS SATIVUS) RADISH ROOTS
}

\section{NOVI YANTIH ${ }^{*}$, WINDA DESTIANA ${ }^{1}$, DIAH KARTIKA PRATAMI ${ }^{1}$}

\author{
${ }^{1}$ Faculty of Pharmacy, Pancasila University, Jakarta, 12640, Indonesia
}

*Email: novi_yantih@yahoo.com

Received: 06 Sep 2020, Revised and Accepted: 09 Oct 2020

\section{ABSTRACT}

Objective: The purpose of this research is to explore the in vitro activities of white (Raphanus raphanistrum) and red (Raphanus sativus) radish root ethanol extract in decreasing cholesterol levels.

Methods: Ultrasonification method was used in obtaining $96 \%$ ethanol extract of white and red radish root. The cholesterol levels were analyzed by visible spectrophotometry, which was validated using Lieberman-Buchard reagents. The decreased cholesterol levels were converted into IC 50 values.

Results: The results showed that the $\mathrm{IC}_{50}$ of $96 \%$ white and red radish root ethanol extracts were 743.7 and $634.7 \mu \mathrm{g} / \mathrm{ml}$, respectively. The results of statistical analysis using the T-test obtained a significant value greater than the probability value (P) of 0.05 .

Conclusion: Therefore, it was concluded that the activities of $96 \%$ ethanol extract of white and red radish roots did not have a significant ability to reduce the in vitro cholesterol levels.

Keywords: Raphanus raphanistrum, Raphanus sativus, Cholesterol, Spectrophotometry

(C) 2021 The Authors. Published by Innovare Academic Sciences Pvt Ltd. This is an open access article under the CC BYlicense (http://creativecommons.org/licenses/by/4.0/) DOI: http://dx.doi.org/10.22159/ijap.2021.v13s2.05 Journal homepage: https://innovareacademics.in/journals/index.php/ijap

\section{INTRODUCTION}

Cholesterol is a substance in the body useful in helping the formation of cell walls, bile salts, steroid hormones, and vitamin D, as well as producing energy. It is majorly sourced from the liver (about 70\%), while the rest is from the food entering the body. Cholesterol has a positive impact on the body; however, when higher than the normal limit, it results to a negative effect on human health [1]. Furthermore, its excess pose a serious threat to the body, causing various infections, such as atherosclerosis (narrowing of blood vessels), coronary heart disease, stroke, hypertension, and hypercholesterolemia [2]. However, it is prevented using synthetic drugs or those derived from natural ingredients.

White (Raphanus raphanistrum) and red (Raphanus sativus) radish plants are known to have anti-cholesterol activity since they contain chemical substances such as flavonoids, saponins, pectins, phospholipids, and Hydroxymethylglutaryl-CoA (HMG-CoA) reductase [3]. Furthermore, pectin bind to low-density lipoprotein (LDL) and very-low-density lipoprotein (VLDL) cholesterol causing plaque in blood vessels. Conversely, positive High-density lipoprotein (HDL), which is responsible for the removal of sedimentation (plaque) from the blood vessels and arteries, is not bound and remains in the body [4].

The research by Mozamel Haque et al. stated that radish water extract reduces the risk of cardiovascular disease in hypercholesterolemic conditions by increasing plasma cholesterol clearance and repairing oxidative damage of liver tissue [5]. The results showed that hypercholesterolemia increased the total cholesterol and triglycerides in the plasma and liver. Meanwhile, the amount of alanine aminotransferase, aspartate aminotransferase, and alkaline phosphate also increases. The provision of radish extract to rats with hypercholesterolemia returned the levels of their liver enzymes (alanine aminotransferase, aspartate aminotransferase, and alkaline phosphate) to normal. The radish extract significantly reduces the amount of lipid peroxidase, causing a decrease in LDL cholesterol of the liver, and provides protection from oxidative stress attacks [5]. Meanwhile, Mona Mohamed Abdel Magied et al. stated that red radish methanol extract lowers the total cholesterol better than the white, due to its high phenolic compounds [6]. The main chemical constituents of radishes are potassium, sodium, magnesium, phosphorus, sulfur, and several water-soluble vitamins, such as vitamins B1, B2, and C [5]. Furthermore, radish roots and leaves contain various chemical constituents, such as saponins, flavonoids, and essential oils [7].

The purpose of this research is to explore the in vitro activities of white and red radish root ethanol extracts in decreasing cholesterol levels. Meanwhile, ethanol is a universal solvent, non-toxic, and less dangerous than methanol. The UV-Vis spectrophotometric method is used in measuring the reduction in cholesterol levels of white and red radish ethanol extracts. The measurement principle is to react the cholesterol solution with the Lieberman-Burchard reagent and observing it through a light spectrophotometer [8]. This method has been used previously in the research to determine the cholesterol levels from water and ethanol extract of okra fruits Abelmoschus esculentus (L.) Moench.) [9]. However, in this study, the visible light spectrophotometric method was validated using LiebermanBurchard reagent for cholesterol reduction test of white and red radish ethanol extracts. The validation method was then used for the comparative study of cholesterol reduction from the ethanol extract of white and red radish.

\section{MATERIALS AND METHODS}

\section{Materials}

The materials used were one year old white (Raphanus raphanistrum) and red (Raphanus sativus) radish roots, which were examined in the Herbarium Bogoriense, Botanical Sector, Biological Research Center-Indonesian Institute of Sciences (LIPI) Cibinong, Bogor, West Java, Indonesia with plant identification No. 2439/IPH.1.01/If.07/XI/2017. While the remaining materials included $96 \%$ ethanol, anhydrous acetic acid, concentrated sulfuric acid, comparison standard of cholesterol and chloroform were purchased from Sigma-Aldrich (Merck KGaA, Missouri, United States). Nitrogen gas as a carrier in gas chromatography was purchased from Q-Lab (Faculty of Pharmacy, Pancasila University, Jakarta, Indonesia).

\section{Research tools}

The tool used was UV-VIS spectrophotometer Shimadzu UV 1800 (Shimadzu, Japan), a gas chromatography Hewlett Packard 6890 
series (Hewlett-Packard, Palo Alto, CA, USA) equipped with a flame ionization detector, and a $30 \mathrm{~mm} \times 0.32 \mathrm{~mm}$ column containing a TRWAX stationary phase with a particle size of 100 to 120 mesh, rotary vacuum evaporators Buchi B480 (Büchi LaboratoriumsTechnik, Flawil/Schweiz, Switzerland), vortex device Vortex V1 Plus (Boeco, Germany), and analytical scales (Mettler Toledo AG, GreifenseeZürich, Switzerland).

\section{Preparation of $96 \%$ radish root ethanol extract}

The preparation of Simplicia powder was carried out using a sample of radish roots that had been washed, peeled, thinly chopped, dried, mashed, and sieved with a sieve No.4/18. Then, as much as $20 \mathrm{~g}$ was weighed and placed in a container for sonication extraction using $96 \%$ of $200 \mathrm{ml}$ ethanol for $30 \mathrm{~min}$ at room temperature. The sample solution was filtered and concentrated using a rotary vacuum evaporator until a thick extract was obtained and determined. The yield and (Drug extract ratio) DER-native of the extract was calculated with Equation 1 and 2:

$$
\begin{gathered}
\text { Yields }=\frac{\text { Amount of extract }(\text { gram })}{\text { Simplicia powder }(\text { gram })} \\
\text { DER-native }=\frac{\text { Simplicia powder }(\text { gram })}{\text { Amount of extract }(\text { gram })} .
\end{gathered}
$$

\section{Characterization of powder and extract quality}

The powder quality characterization included water content test [10], drying loss assessment [10], and phytochemical screening [11]. The extract quality characterization was similar to that of powder, and added with the test for the residual level of ethanol solvent.

\section{In vitro test for decreasing cholesterol levels after interacting} with white and red radish root extracts

The standard solution was prepared at a concentration of 2000 $\mu \mathrm{g} / \mathrm{ml}$ by dissolving $500 \mathrm{mg}$ of cholesterol powder in $250.0 \mathrm{ml}$ of methanol-chloroform (1:9) and stirring until they homogenized. The extract solution was prepared at a concentration of $2000 \mu \mathrm{g} / \mathrm{ml}$ by dissolving $400 \mathrm{mg}$ of the isolate in $200.0 \mathrm{ml}$ of methanol-chloroform (1:9). The Liberman Buchard reagent solution was made by mixing $0.5 \mathrm{ml}$ of concentrated sulfuric acid with $10 \mathrm{ml}$ of anhydrous acetic acid.

The maximum absorption wavelength $(\lambda)$ was determined using UVVis spectrophotometry by scanning the $\lambda$ of cholesterol made from a standard solution of $0.5 ; 1.0$; and $1.5 \mathrm{ml}$, added with $10.0 \mathrm{ml}$ methanol-chloroform (1:9). Subsequently, $5 \mathrm{ml}$ standard solution was pipetted into a tube covered with aluminum foil to protect it from light, and reacted with $3.0 \mathrm{ml}$ of Liebermann-Burchard reagent. Furthermore, it was left for $15 \mathrm{~min}$ until it formed a green colour change. The solution was measured using a UV-Vis spectrophotometer at $\lambda 300-800 \mathrm{~nm}$.

The operating time was determined from the cholesterol standard solution, which was similar to that of maximum absorption $\lambda$. The solution was then measured every 2 min starting from 8 to $30 \mathrm{~min}$ using the maximum absorption $\lambda$ for cholesterol detection.

The linearity of the method was carried out by determining the line equation between the extract concentration and the absorption. From the standard cholesterol solution with a concentration of 2000 $\mu \mathrm{g} / \mathrm{ml}, 3.0 \mathrm{ml}$ was taken and added to the extract solution with a concentration of $375,500,625,750,875 \mu \mathrm{g} / \mathrm{ml}$ and added with 10.0 $\mathrm{ml}$ methanol-chloroform (1:9). The line equation was obtained from the relationship between the concentration of extract and the absorption. A linear relationship was achieved when the determination coefficient $\left(\mathrm{R}^{2}\right)$ approached 1 [12]. From the equation $y=a+b x$ curve, the $\mathrm{IC}_{50}$ of cholesterol reduction was determined after interacting with the extract by including $y=50$.

The accuracy was accomplished with the first and second accuracy test. The first accuracy test was carried out by making a standard cholesterol solution of $2000 \mu \mathrm{g} / \mathrm{ml}$, taken $3.0 \mathrm{ml}$ and added with the extract of $\mathrm{IC}_{50}$ concentration. Furthermore, as much as $5 \mathrm{ml}$ was pipetted and left according to its operating time and the absorption was measured at maximum $\lambda$, and repeated ten times. The second accuracy test was carried out on a cholesterol standard of $375 \mu \mathrm{g} / \mathrm{ml}$ with $30 \%$ extract IC $_{50}$ concentration. The cholesterol standard solution of $2000 \mu \mathrm{g} / \mathrm{ml}$ was pipetted as much as $3.0 \mathrm{ml}$ and added to an extract concentration $\mathrm{IC}_{50}$. Furthermore, 30\% extract was added from $\mathrm{IC}_{50}$ concentration and the volume was increasd to $10.0 \mathrm{ml}$. Subsequently, $5 \mathrm{ml}$ of the solution was pipetted and repeated ten times.

The precision of the method used was determined based on the relative standard deviation. In this study, the precision was determined from the recovery data. Meanwhile, the limits of detection and quantitation were calculated statistically through the linear regression from the linearity test.

In vitro anti-cholesterol activities of white and red radish root ethanol extract

The cholesterol standard solution with a concentration of $2000 \mu \mathrm{g} / \mathrm{ml}$ was made into 5 concentration series and was taken as much as $1.0 ; 1.5 ; 2.0 ; 2.5$; and $3.0 \mathrm{ml}$ and added to $10.0 \mathrm{ml}$ methanolchloroform (1:9), respectively, and subsequently pipetted as much as $5 \mathrm{ml}$. Then, a curve of the relationship between the cholesterol standard concentration and its absorption was made. The in vitro studies on the activities of white and red radish extracts in decreasing cholesterol levels were determined in the linearity test. In this study, the negative control was cholesterol solution at a concentration of $375 \mu \mathrm{g} / \mathrm{ml}$ in methanol-chloroform.

\section{RESULTS AND DISCUSSION}

\section{Preparation of simplicia powder}

The simplicia powder of white and red radish roots was uniformed in size through sieving. The measurement results for the fine simplicia powder was shown in table 1 .

Table 1: The measurement results for the fine degree of simplicia powder

\begin{tabular}{lll}
\hline Simplicia & Passed the number 4 sieve (\%) & Passed the number 18 sieve (\%) \\
\hline White Radish & 100 & 24.44 \\
Red Radish & 100 & 28.86 \\
\hline
\end{tabular}

The measurement results for the fine simplicia powder on the $4 / 18$ sieve showed that the powder fulfilled the requirements of Materia Medika Indonesia, since it passed $100 \%$ on the number 4 sieve, and $40 \%$ on the number 18 sieve. The purpose of measuring was to ensure that the powder has a small size, therefore, expanding their contact with the solvent.

\section{Preparation of $96 \%$ radish root ethanol extracts}

This study used white and red radish extracts isolated using 96\% ethanol solvent by ultrasonification. The results of Drug Extract Ratio (DER-native) analysis and the yield from white and red radish ethanol extracts preparation were shown in table 2.

Table 2: DER-native and yields of white and red radish ethanol extracts

\begin{tabular}{lll}
\hline Simplicia & DER-native & Yield (\%) \\
\hline White Radish & $12.10 \pm 0.94$ & $8.30 \pm 0.63$ \\
Red Radish & $12.61 \pm 0.76$ & $7.97 \pm 0.46$ \\
\hline
\end{tabular}

Data were given in mean $\pm S D, n=6$ 
The extracts were made to react with the secondary metabolites present in radish using 96\% ethanol as a solvent. In this study, the ultrasonification method used was only able to extract a maximum of $50 \mathrm{~g}$; therefore, the extraction was carried out repeatedly to obtain the amount needed. The DER-native analysis showed the ratio between the simplicia and the extract weight obtained. Also, it was used to calculate the extract amount required for phytochemical screening. Meanwhile, the yield showed the percentage of extract weight obtained from that of Simplicia used. The extraction yield was still quite small (less than 10\%); therefore, other isolation techniques were developed to increase it.

\section{Characterization of powder and extract quality}

The characterization for the quality of powder and ethanol extract of white and red radish roots were shown in table 3.

Table 3: The characterization of powder and extract of white and red radish roots

\begin{tabular}{lllll}
\hline S. No. & Characterization & White radish & Red radish \\
\cline { 3 - 5 } & & Simplicia powder & Extract & Simplicia powder \\
\hline 1. & Flavonoids & + & + & + \\
2. & Saponins & + & + & + \\
3. & Tannins & - & + & - \\
4. & Steroids/Triterpenoids & + & 5.62 & + \\
5. & Water content (\%) & 3.99 & 8.28 & 4.97 \\
6. & Drying Losses (\%) & Not carried out & Not carried out & + \\
7. & Ethanol Solvent Residue (\%) & Not carried out & Not carried out & 7.77 \\
\hline
\end{tabular}

Note: $(+)$ symbol indicates a positive reaction, $(-)$ symbol indicates a negative reaction

The phytochemical screening was used to determine the secondary metabolite compounds contained in the simplicia powders and extracts. The White and red radish powder and the extracts were known to contain flavonoids, saponins, steroids, and triterpenoids (table 3). The phytochemical screening was identified only in the flavonoids, saponins, tannins, and steroids/triterpenoids since the cholesterol-lowering activity were found in these groups.

Besides phytochemical screening, the quality characterization carried out was the test of moisture content, drying losses, and the ethanol solvent residue. Based on the examination results, the water content of white and red radish Simplicia isolates were $3.99 \%$ and $4.97 \%$, respectively, while that of ethanol extracts were $5.62 \%$ and $6.06 \%$, respectively. Therefore, the water content of ethanol was relatively greater than that of Simplicia powder. Based on the standard parameters of plant extract quality, the requirement for water content was not more than $10 \%$ [13]. The water content in the simplicia extract and the powder was in accordance with the Indonesian Food and Drug Supervisory Agency Regulation Number 12 of 2014 on Quality Requirements for Traditional Medicines [13]. The water content examination was useful for maintaining the quality of extracts produced; therefore, the less water content in the simplicia and extracts, the less possibility of microbial growth. Since the water was an excellent medium for microbial growth.

Based on the results of drying losses determination, the white and red radish ethanol extracts were $8.28 \%$ and $7.45 \%$, respectively. The drying losses determination was intended to show the water content, volatile substances, and thermolable compounds that evaporated after heating at $1050 \mathrm{C}$. The $96 \%$ ethanol extract of white and red radish had a residual solvent content of $0.77 \%$ and $0.62 \%$, respectively. The examination results correlated with the requirements for the maximum residual solvent limit in the extract, namely $\leq 1 \%$ [14].

\section{Optimization method}

In the anti-cholesterol activity test of white and red radish root ethanol extracts, the methanol-chloroform mixed solvent was used to increase their solubility. Cholesterol was a non-polar compound that dissolves in non-polar solvents, while the ethanol extract of white and red radish was more polar. Therefore, it required a solvent that is capable of dissolving the two substances. In previous studies, the methanol-chloroform solvent was used to test the anticholesterol activity of avocado seeds (9). The maximum absorption wavelength of cholesterol solution in methanol-chloroform solvent was optimized at 3 different concentrations to determine the peak that produced the maximum and stable absorption response. In this experiment, the maximum absorption wavelength was $674 \mathrm{~nm}$, shown in fig. 1.

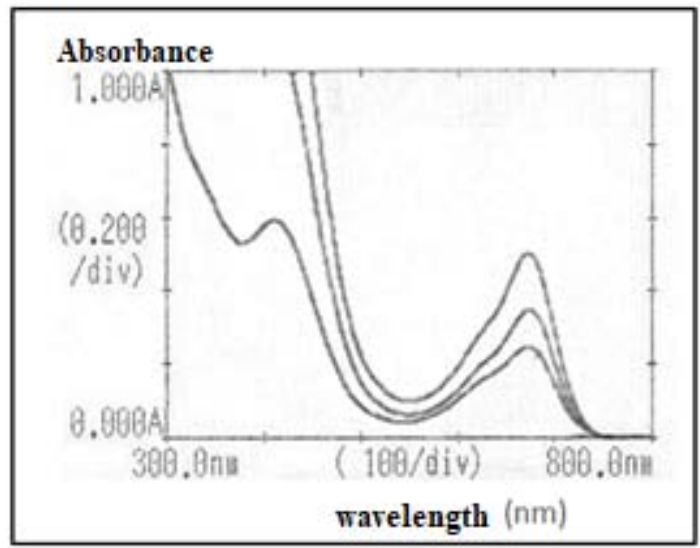

Fig. 1: The maximum absorption wavelength of cholesterol standard solution

The wavelength determination was carried out to ascertain the value that provides the maximum absorption of cholesterol standard solution. In this experiment, the maximum absorption wavelength was $674 \mathrm{~nm}$. The peaks observed in the spectrum were in the wavelength of around $400 \mathrm{~nm}$ (green) [15]. Although the absorption response was higher, they were not selected due to their instability, indicating that the complement of green test solution was red at the wavelength of 620-700 $\mathrm{nm}$ [15].

In this study, the stable time determination was carried out to ascertain the stability of standard cholesterol solution using Lieberman-Buchard reagent for a certain period of time. From the research results, it was found that the stable time of cholesterol standard solution, which reacted with the Lieberman-Buchard reagent, was at 18 to $22 \mathrm{~min}$. Therefore, the measurements were made directly at the stable time, shown in fig. 2 .

\section{Method validation}

The analysis method validation performed were linearity, accuracy, precision, detection and quantitation limits. And were carried out at optimum conditions, namely a wavelength of $674 \mathrm{~nm}$ and at a stable time of 18-22 $\mathrm{min}$.

The linearity test was carried out using three standard series of cholesterol added with $96 \%$ ethanol extract of white or red radish roots with different concentrations. The results were shown in fig. $3-4$. 


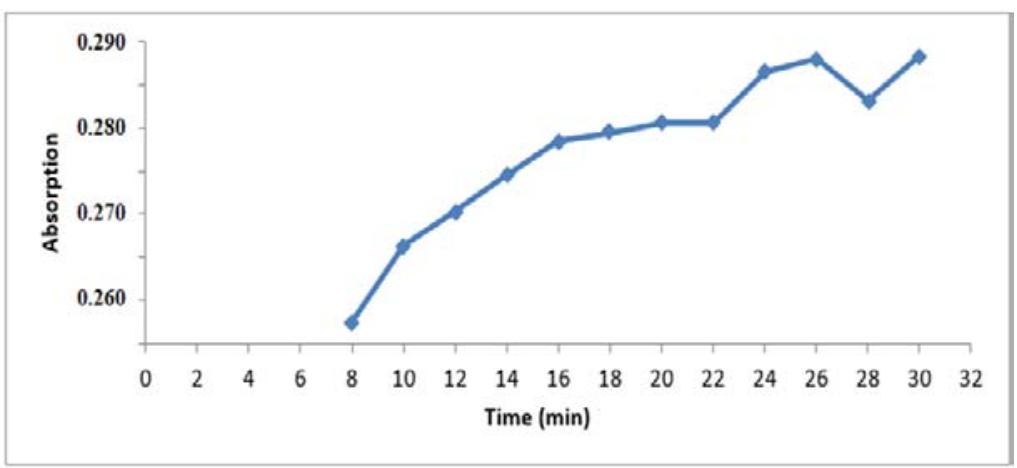

Fig. 2: The absorption profile of the standard cholesterol solution with Lieberman buchard reagent against time for $30 \mathrm{~min}$

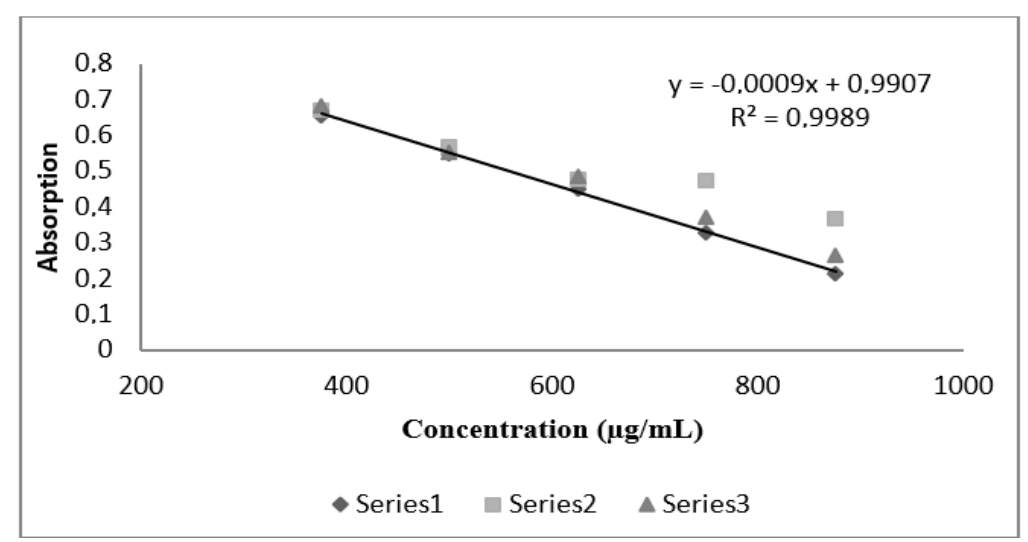

Fig. 3: The concentration of white radish root extract vs cholesterol standard solution

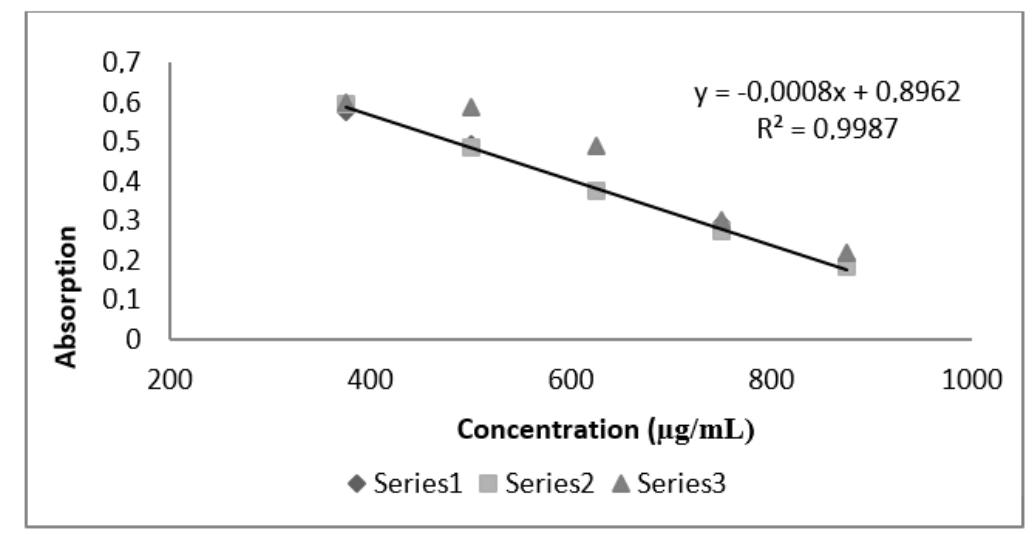

Fig. 4: The concentration of red radish root extract vs cholesterol standard solution

The linearity results of $96 \%$ white and red radish root ethanol extract had a linear relationship with the determination coefficient $\left(\mathrm{R}^{2}\right)$ close to 1 [12].

The accuracy test was a recovery examination carried out by adding a certain amount $(30 \%)$ of the extract from the IC50 concentration, then measured using visible light spectrophotometry according to the maximum wavelength. The average recovery test results of white and red radish root ethanol extracts were 93.68 and $93.61 \%$, respectively (table 4). The recovery results obtained were consistent with the requirements of $90-107 \%$ [12]. This showed that the spectrophotometric method had the accuracy that was used to determine the decrease in cholesterol levels. Based on the SBR recovery results of the method in the matrix of white and red radish root extracts, the values were 1.93 and $1.80 \%$, respectively. Therefore, the precision results were consistent with the requirements of $<8 \%$ [12].

Table 4: Recovery results of white and red radish root ethanol extract

\begin{tabular}{lll}
\hline Simplicia & Recovery results (\%) & Relative standard deviation (\%) \\
\hline White Radish & $93.68+1.80$ & 1.93 \\
Red Radish & $93.61+1.68$ & 1.80 \\
\hline
\end{tabular}

Data were given in mean $\pm S D, n=10$ 
The detection limit was the smallest in the sample that was detected. Therefore, the detection limit of the method based on linearity data using the equation $y=-0.0009 x+0.9907$ with $R^{2} 0.9989$ was 22.96 $\mu \mathrm{g} / \mathrm{ml}$. While the detection based on the regression equation $\mathrm{y}=-$ $0.0008 \mathrm{x}+0.8962$ with $\mathrm{R}^{2} 0.9987$ was $25.3 \mu \mathrm{g} / \mathrm{ml}$. The quantitation limit was a parameter in the microscopic analysis and defined as the smallest analytical quantity in a sample that correlated with the given criteria. The quantitation limit of the method based on the same linearity data showed a result of 76.5 and $84.20 \mu \mathrm{g} / \mathrm{ml}$, respectively.
In vitro study on the activities of the white and red radish root extract in decreasing cholesterol levels

In vitro studies of reduction in cholesterol levels after interacting with white and red radish root extracts were determined using the regression equation of standard solution curve. Based on the experimental results, the standard curve of cholesterol from the correlation between absorption and concentration solution showed a linear relationship with the regression line equation, namely $\mathrm{y}=$ $0.0656+0.0019 x$ with $R^{2}$ value of 0.99855 (fig. 5).

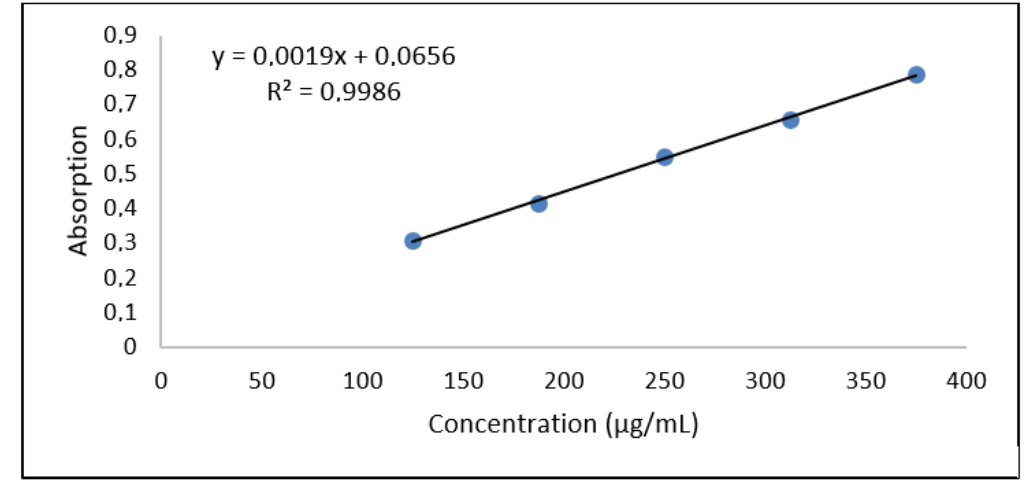

Fig. 5: Graph of cholesterol solution standard curve

Based on the results of the comparative study, the cholesterol levels in the test solution decreased with an increase in the concentration of white and red radish root ethanol extracts, as shown in fig. 6-7.

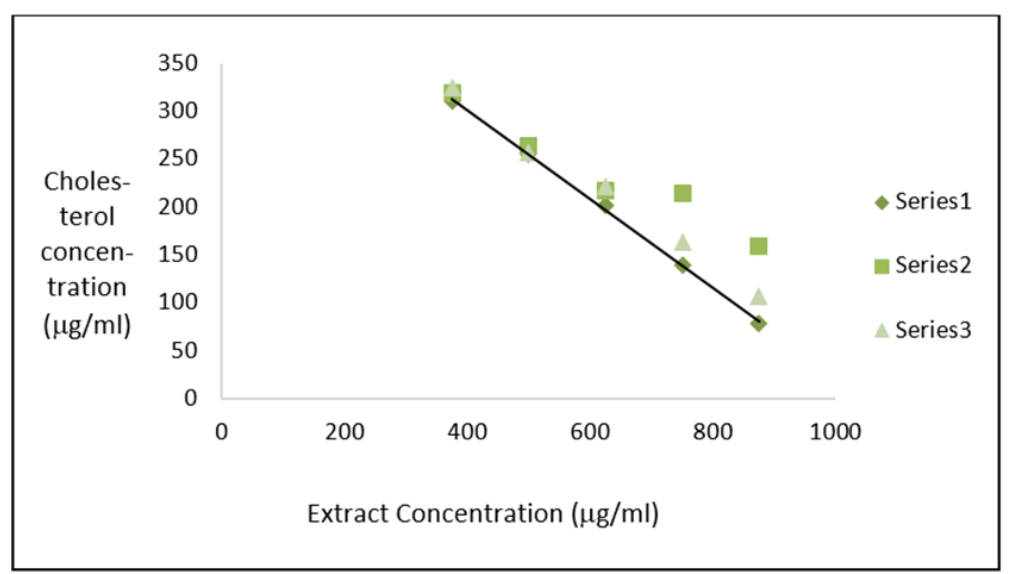

Fig. 6: Relationship curve between cholesterol concentration and white radish root extract concentration

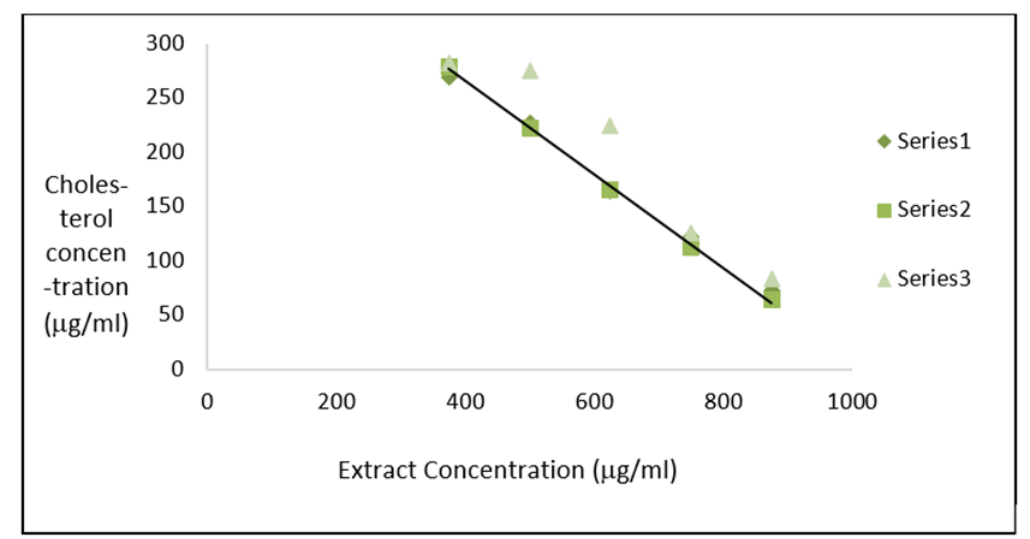

Fig. 7: Relationship curve between cholesterol concentration and red radish root extract concentration 
The cholesterol-lowering activity was compared based on the $\mathrm{IC}_{50}$ value (Inhibition Concentration 50 ). The $\mathrm{IC}_{50}$ value had the ability of reducing cholesterol by $50 \%$ from its initial concentration after interacting with the extract. Based on the data results, the $\mathrm{IC}_{50}$ value of white and red radish root ethanol extract were 743.7 and $634.7 \mu \mathrm{g} / \mathrm{ml}$, respectively (fig. 8). The result of homogeneity test analysis showed a significance value of 0.224 . This was greater than the probability value $(p)=0.05$, which indicated a homogeneous data distribution; therefore, further analysis was needed using T-test. The T-test results showed that the significance value was greater than the probability degree $(p)=0.05$, indicating that the statistical test accepted H0. Based on the statistical test of $\mathrm{IC}_{50}$ value, it was concluded that there was no significant difference between the ethanol extract of white and red radish roots in their activity in decreasing cholesterol levels.

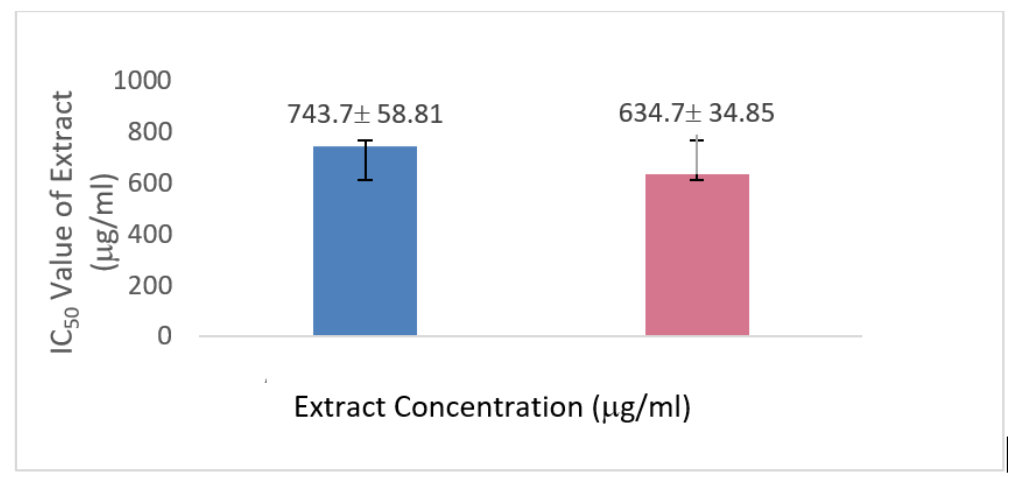

Fig. 8: Graph of $\mathrm{IC}_{50}$ for $96 \%$ white and red radish root ethanol extract

The cholesterol-lowering activity of white and red radish root extracts was due to their chemical contents, such as flavonoids and saponins obtained from the 2nd phytochemical screening of extracts in table 3. The flavonoids were known to inhibit the synthesis of cholesterol, triglycerides, and phospholipids, and HMG-COA reductase [16]. While the saponin extracts of Garcinia cola roots were known to reduce the total cholesterol in plasma [16].

\section{CONCLUSION}

The ethanol extract of white (Raphanus raphanistrum) and red (Raphanus sativus) radish roots did not have a significant difference in their activity to reduce cholesterol levels based on the statistical analysis at $95 \%$ confidence level.

\section{ACKNOWLEDGMENT}

The author gratefully acknowledges to thank the Q-lab and Research Laboratory Faculty of Pharmacy University of Pancasila who have provide facilities for this research.

\section{FUNDING}

Nil

\section{AUTHORS CONTRIBUTIONS}

All authors Novi Yantih (NY), Winda Destiana (WD), Diah Kartika Pratami (DKP) discussed the results and contributed to the final manuscript. NY has conceived of the presented idea, supervised the findings of this work and verified the analytical methods. WD has carried out the experiment, performed the analytic calculations and performed the numerical simulations DKP developed the standardization of extract, performed the computations and contributed to the final version of the manuscript.

\section{CONFLICT OF INTERESTS}

The authors declare no conflict of interest.

\section{REFERENCES}

1. Olsson AG, Angelin B, Assmann G, Binder CJ, Bjorkhem I, Cedazo Minguez A, et al. Can LDL cholesterol be too low? Possible risks of extremely low levels. J Intern Med 2017;281:534-53.

2. Moghimipour E, Kooshapour H, Rezaee S, Khalili S, Handali S. In vitro cholesterol-binding affinity of total saponin extracted from Glycyrrhiza glabra. Asian J Pharm Clin Res 2013;7:170-3.
3. Metwally MA, El-Gellal AM, El-Sawaisi SM. Effects of silymarin on lipid metabolism in rats. World Appl Sci 2009;6:1634-7.

4. Okazaki M, Morio Y, Iwai S, Miyamoto K, Sakamoto H, Imai K, et al. Age-related changes in blood coagulation and fibrinolysis in mice fed on a high-cholesterol diet. Exp Anim 1998;47:237-46.

5. Haque M, Islam J, Rahaman A, Selina FA, Azizur M, Rahman MH, et al. Raphanus sativus ameliorates atherogeneic lipid profiles in hypercholesterolemic rats and hypercholesterolemiaassociated peroxidative liver damage. J Adv Chem 2014:7:1385-94.

6. Magied MMA, Alian AM, haerrdy L, Hussein MT. The protective effect of white and red radish as hypoglycemic and hypocholesterolemic agents. J Pharm Biol Sci 2016;11:51-61.

7. Shin T, Ahn M, Kim GO, Park SU. Biological activity of various radish species. Orient Pharm Exp Med 2015;15:105-11.

8. Gashaw A, Getachew T. Cholesterol content and free fatty acids in edible oils and health effects: a review. Int J Res Appl Sci Eng Technol 2014;2:120-5.

9. Djamil R, Zaidan S, Butar VB, Pratami DK. Formulasi nanoemulsi ekstrak etanol buah okra (Abelmoschus esculentus (L.) Moench.) dan uji aktifitas antikolesterol secara in vitro. J Ilmu Kefarmasian Indones 2020;18:75-80.

10. Djamil R, Zaidan S, Rahmat D, Pratami DK, Hakim F. Nanoemulsion of okra fruit extract as antidiabetic treatment. Int J Appl Pharm 2020;12:138-42.

11. Farnsworth NR. Biological and phytochemical screening of plants. J Pharm Sci 1966;55:225-76.

12. Brittain HG. editor. Profiles of drug substances, excipients, and related methodology. London: Academic Press; 2020.

13. Yantih N, Methananda A, Harahap Y, Sumaryono W, Rahayu L. Validation of high-performance liquid chromatography for determination of bromelain in pineapple (Ananas comosus (L) Merr) water. Pharmacogn J 2019;11:901-6.

14. Martono Y, Rohman A. Quantitative analysis of stevioside and rebaudioside a in Stevia rebaudiana leaves using infrared spectroscopy and multivariate calibration. Int J Appl Pharm 2019;11:38-42.

15. Lotfy HM. Determination of simvastatin and ezatimibe in combined tablet dosage forms by constant center spectrophotometric method. Int J Pharm Pharm Sci 2012;4:673-9.

16. Adanlawo IG. Tissue lipid profile of rats administered saponin extract from the root of bitter kola. Biochemistry 2013;1:1-4. 